\title{
Impact of the European Russia drought in 2010 on the Caspian Sea level
}

\author{
K. Arpe ${ }^{1,2}$, S. A. G. Leroy ${ }^{2}$, H. Lahijani ${ }^{3}$, and V. Khan ${ }^{4}$ \\ ${ }^{1}$ Max Planck Institute for Meteorology, Hamburg, Germany \\ ${ }^{2}$ Institute for the Environment, Brunel University, Uxbridge, London, UK \\ ${ }^{3}$ Iranian National Institute for Oceanography (INIO), Tehran, Iran \\ ${ }^{4}$ Hydrometeorological Research Center of the Russian Federation, Moscow, Russia \\ Correspondence to: S. A. G. Leroy (suzanne.leroy@brunel.ac.uk)
}

Received: 23 July 2011 - Published in Hydrol. Earth Syst. Sci. Discuss.: 15 August 2011

Revised: 6 December 2011 - Accepted: 14 December 2011 - Published: 3 January 2012

\begin{abstract}
The hydrological budgets of the Volga basin (VB) and the Caspian Sea (CS) have been analysed. The components of the water balance for the CS were calculated for the period 1993 to 2010 with emphasis on summer 2010 when a severe drought developed over European Russia.
\end{abstract}

A drop in precipitation over the VB in July 2010 occurs simultaneously with a decrease in evaporation for the same area, an increase of evaporation over the CS itself and a drop of the Caspian Sea level (CSL). The drop in the precipitation over the VB cannot lead to an instantaneous drop of the CSL because the precipitated water needs some months to reach the CS. The delay is estimated here to be 1 to 3 months for excessive precipitation in summer, longer for deficient precipitation and for winter cases. However, the evaporation over the CS itself is considered to be responsible for a simultaneous drop of the CSL from July to September 2010. The impact on the CSL from the precipitation deficit over the VB occurs in the months following the drought. The water deficit from July to September 2010 calculated from the anomalous precipitation minus evaporation over the VB would decrease the CSL by $22 \mathrm{~cm}$, of which only $2 \mathrm{~cm}$ had been observed until the end of September (observed Volga River discharge anomaly). So the remaining drop of $20 \mathrm{~cm}$ can be expected in the months to follow if no other anomalies happen. In previous studies the precipitation over the VB has been identified as the main cause for CSL changes, but here from a $10 \mathrm{~cm}$ drop from beginning of July to end of September, $6 \mathrm{~cm}$ can be directly assigned to the enhanced evaporation over the CS itself and $2 \mathrm{~cm}$ due to reduced precipitation over the CS.

Further periods with strong changes of the CSL are also investigated, which provide some estimates concerning the accuracy of the analysis data. The investigation was possible due to the new ECMWF interim reanalysis data which are used to provide data also for sensitive quantities like surface evaporation and precipitation. The comparison with independent data and the consistency between such data for calculating the water budget over the CS gives a high confidence in the quality of the data used.

This investigation provides some scope for making forecasts of the CSL few months ahead to allow for mitigating societal impacts.

\section{Introduction}

A blocking anticyclone persisted for 55 days over the central part of European Russia including the Volga basin (VB) from the end of June 2010. Extreme hot air inflow from Middle Asia into European Russia occurred. Absolute maxima of mean daily air temperature were recorded during this period exceeding normal values by 6 to $10^{\circ} \mathrm{C}$ (Parshina, 2010; Barriopedro et al., 2011). The extreme hot and dry conditions led to widespread crop losses and wild forest and grassland fires which were widely reported by the media. In this study the impacts of this drought on the Caspian Sea level (CSL) are investigated.

The Caspian Sea (CS) $\left(36-47^{\circ} \mathrm{N}, 47-54^{\circ} \mathrm{E}\right)$ is a closed basin without any outlet. Its sea level lies around $26 \mathrm{~m}$ below the mean sea level of the oceans ( -25 to $-29 \mathrm{~m}$ during the last $150 \mathrm{yr}$ ). Its main water source is the Volga River whose catchment area reaches well into the humid mid-latitudes and which was widely affected by the recent Russian drought. The water inflow is balanced by evaporation $(E)$ over the CS itself including the Kara Bogaz Gol (KBG). The CSL variability and the water budget of the CS have been investigated in previous studies, e.g. Rodionov (1994), Golitsyn (1995),

Published by Copernicus Publications on behalf of the European Geosciences Union. 
Arpe et al. (2000) and Arpe and Leroy (2007). Ozyavas et al. (2011) investigated the water budget for the CS and assigned imbalances to tectonic forces. Several investigations on the CSL changes used climate models to estimate the CSL of the past or for the future. The climate of the last glacial maximum was addressed by Kislov and Toropov (2007). By using different scenarios for the 21st century, the CSL was predicted e.g. by Meleshko et al. (2008) and Arpe and Leroy (2007). Here we concentrate on CSL variabilities and CS budget changes on a much shorter time scale and also with smaller amplitudes using improved data.

During summer 2010, the precipitation was only 10 to $30 \%$ of the normal value in the VB region (Parshina, 2010). As the precipitation $(P)$ over the VB was especially strongly hit by the summer drought in 2010 , it was most likely that this would have an impact on the CSL as suggested already in September 2010 by Lahijani et al. (2010). This study deals with the drought intensity and connections with other climatic parameters. It is investigated how far presently available data allow a calculation of various components of the hydrological budget and how far their impacts on the CSL can be identified. For such investigations, extreme events like this one are beneficial because of a better signal to noise ratio. As the complete set of data is available from 1993 onwards, other periods of CSL changes are also studied for a better understanding of the quality and limits of the observed and analysis data.

\section{Observational and analysis data}

Different sources of observational data have been used for calculating the hydrological budget for the CS to get a full picture of the drought impacts on the CSL. These data are mostly available on regular spatial grids which were subsequently averaged for areas of interest.

The recent CSL observations by satellite (Cazenave et al., 1997) are taken from USDA (2011). Lebedev and Kostianoy $(2005,2006)$ compared gauge observations around the CS with altimetry observations from satellite. They point to many uncertainties in both data sets, e.g. large differences in the CSL in different basins and the existence of surges which can be as large as 2 to $3 \mathrm{~m}$ in the northern basin. Their data were available for comparison with the satellite data.

The precipitation over continents up to 2009 is taken from the Global Precipitation Climate Center (GPCC) (Rudolf et al., 2003; GPCC, 2011). GPCC also provides a data set created within a period of two months after observation time which is based on a smaller amount of observational data, called "monitoring product". Because of the short time available for collecting the data, a lower quality of analysis than that of the final product is expected. The monitoring product is made available at a lower resolution than the final data set. GPCC therefore provides a warning not to mix time series based on their different data streams. However, both data sets are here merged to include also the year 2010 (Fig. 1a).

The precipitation over continents and seas is available from the ECMWF interim reanalysis (ERA) (ECMWF, 2011). This is a further development of the ECMWF reanalysis ERA40 by Uppala et al. (2005). An important difference to ERA40 is the usage of a 4-dimensional variational analysis scheme instead of the former 3-dimensional one (Dee et al., 2011). This largely removes the spin-up of precipitation and evaporation in the early forecasts, present in many reanalyses of this kind (Trenberth et al., 2011). Precipitation in this data set is obtained by using many observational data but no precipitation gauge observations and the precipitation is a product of two $12 \mathrm{~h}$ forecasts per day. Anomalies of precipitation estimates by GPCC and ECMWF can hardly be distinguished as seen in Fig. 1a. They correlate well with each other with an anomaly correlation coefficient of 0.92 and one can assume that both are reliable, as they are based on very different observational data and analysis methods. Also the two GPCC data series can hardly be distinguished for the overlapping period. The $2 \mathrm{~m}$ temperatures, wind and evaporation are taken from the ECMWF interim reanalysis. The data are available on a $1.5^{\circ}$ grid. With such a coarse resolution it is not possible to separate the CS from the KBG. Both are therefore treated as one unit and referred to below only as the CS.

Monthly mean Volga River discharge (VRD) data are taken from Dümenil Gates et al. (2000) complemented for the recent period provided by the Hydrological Forecasts Department of the Hydrometeorological Research Center of the Russian Federation.

Arpe et al. (2000) and Arpe and Leroy (2007) found a connection between the CSL variability and ENSO (El Niño Southern Oscillation) and therefore this parameter is also investigated. The US Climate Prediction Center recommends the use of the Oceanic Nino Index (ONI) which is presented here (CPC, 2011). It is based on the eastern tropical Pacific sea surface temperatures (SSTs) in the El Niño areas applying some standardization.

\section{Results}

\subsection{Overall budget}

The VRD observations at the Volgograd power plant were used to test the different components of the hydrological budget (Table 1). Also the estimates by Golitsyn (1995) are given for comparison. $P-E$ values over the VB are too low compared to the observed Volga discharge. Assuming the observed VRD to be correct, one finds an inaccuracy of the VB precipitation of $2 \%$ (if this is the only erroneous quantity) or of VB evaporation of $3 \%$ (if this is the only erroneous quantity). The difference between ERA and GPCC is larger than the deficit of $P-E$ compared to the VRD. This is due 


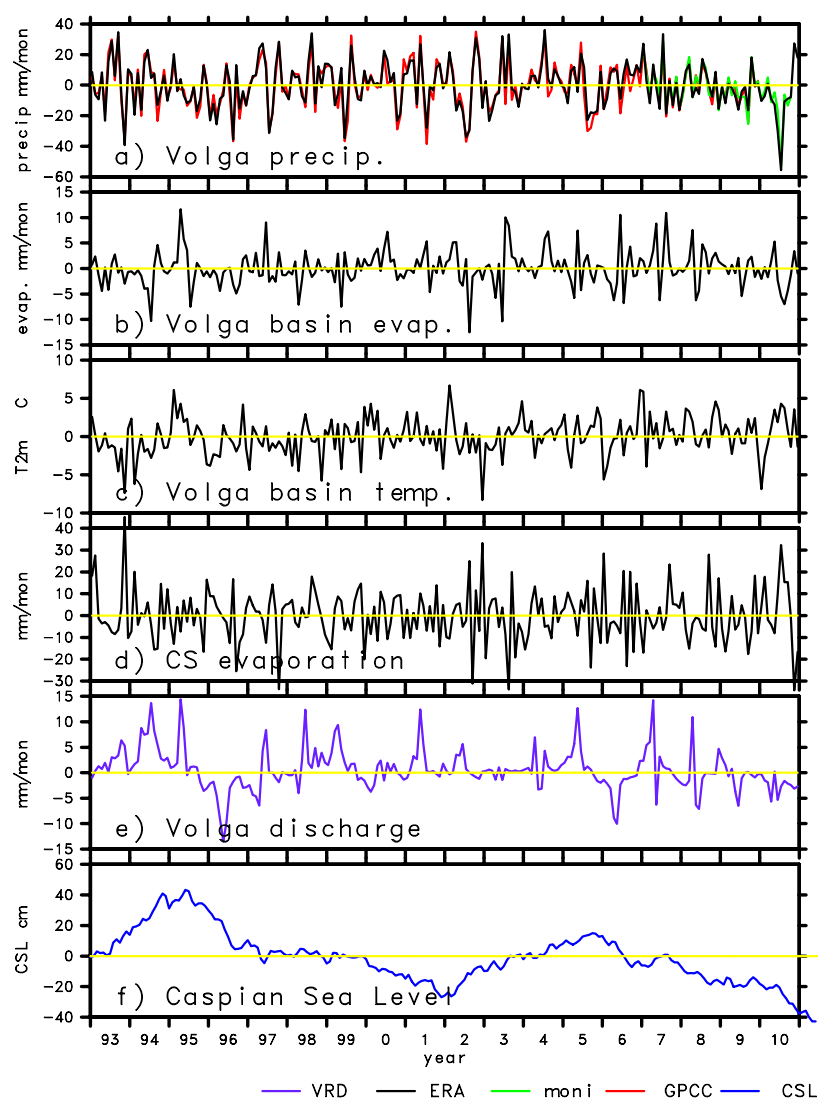

Fig. 1. Time series of monthly mean anomalies, i.e. with the mean annual cycle removed, for a selection of variables. A three month running mean has been applied for smoothing. (a) precipitation over the VB using ERA and GPCC (moni = GPCC monitoring product, GPCC $=$ final product) data, (b) evaporation over the VB, (c) $2 \mathrm{~m}$ temperatures averaged for the VB, (d) evaporation over the CS itself, (e) observed Volga River discharge and (f) CSL. Note that the CSL values are centred on the first of each month while the other quantities are monthly means.

to a missing correction of the GPCC data which is needed to compensate for precipitation undercatchment by gauges which can be large in snow conditions (Sevruk, 1982). Trenberth et al. (2011), who investigated global budgets of water in reanalyses, suggest that the water cycle in reanalyses is too intense probably with too strong evaporation. Over continents the precipitation is probably correct. The water of the Volga is stored in a cascade of reservoirs and partly used for irrigation. This surplus evaporation might however re-enter the budget by extra precipitation and it is not clear if that can be seen in the precipitation analysis. Without taking such a loss into consideration, $P-E$ was already too small compared to the observed VRD.

The VRD contributes normally $80 \%$ of the total discharge into the CS and therefore the values of $P-E$ over the CS are not sufficiently negative, perhaps by $34 \%$. The southern CS is surrounded by high mountains (Leroy et al., 2011) which
Table 1. Climatological water budget components for the Caspian Sea (CS). Units: change of the Caspian Sea level (CSL) per year in $\mathrm{cm} . \mathrm{VB}=$ Volga Basin; $P-E=$ precipitation-evaporation.

\begin{tabular}{lrr}
\hline & $\begin{array}{c}\text { Golitsyn } \\
(1995)\end{array}$ & 1993-2010 \\
\hline VB precipitation ERA (GPCC) & & $232(207)$ \\
VB evaporation & & -167 \\
VB $P$ - $E$ = Volga discharge & & 66 \\
Volga discharge (observed) & 60 & 71 \\
Other rivers & 15 & \\
CS precipitation & 20 & 25 \\
CS evaporation & -95 & -81 \\
CS $P$ - $E$ including Kara-Bogaz-Gol & -75 & -56 \\
Entire Caspian catchment $P$ - $E$ & & 5 \\
CSL change & & -2 \\
\hline
\end{tabular}

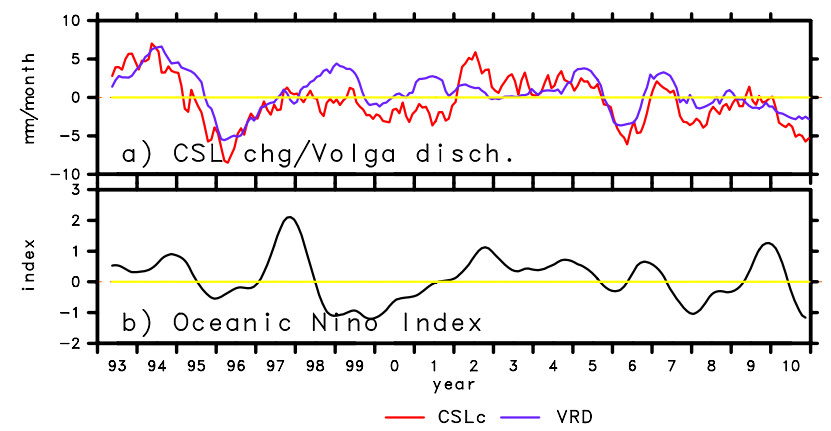

Fig. 2. Time series of monthly mean anomalies, i.e. with the mean annual cycle removed, for (a) the CSL change and the Volga River discharge (values are converted to $P-E$ for the Volga basin catchment area and (b) the Ocean Nino Index. A nine month running mean has been applied for smoothing.

could lead to an underestimation of the surface wind speed and subsequently leading to an underestimation of the evaporation.

Obviously some biases are still present. However the ERA data, averaged for the entire CS catchment area, suggest a change of the CSL for the whole period which differs only by $7 \mathrm{~cm}$ per year from the observed one which is only $3 \%$ of the largest budget term. We are mainly interested how these quantities change over time. Therefore this study focuses on anomalies, this way the impact of systematic errors (longterm mean errors) is reduced. The advantage of looking into anomalies is demonstrated by Fig. 2a that compares the timederivative of the CSL with the VRD. The similarity between both curves is obvious and the correlation is 0.71 .

\subsection{Precipitation - Volga discharge delay}

One has to assume that there is a delay between a precipitation event over the VB and the VRD of some months. We 


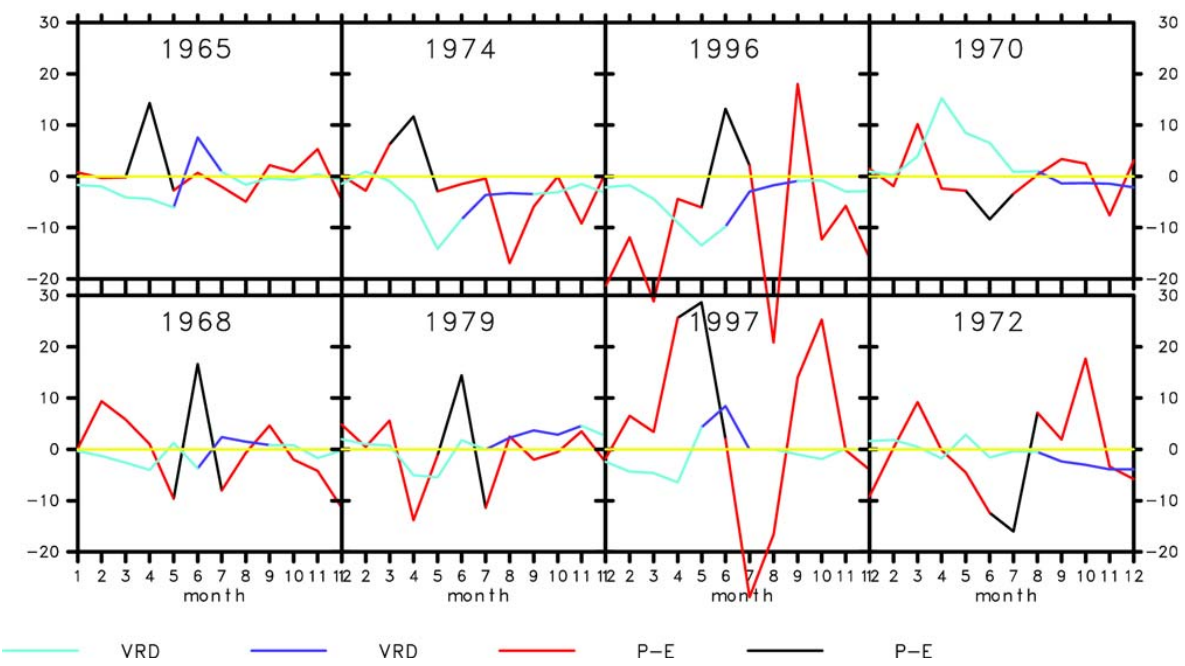

Fig. 3. Selection of years showing extreme events with $P-E$ which are followed by extreme events in the VRD. The events are marked by different colours. The two right ones are those with deficient $P-E$.

tried to quantify the length of this delay. The delay can already be shown by comparing the Volga basin $P-E$ mean annual cycle with that of the VRD. $P-E$ has its maximum from October to February while the VRD has a maximum in May, so there is a clear delay of several months mainly due to storage of water on the ground by ice and snow. For summer the delay is shorter. To show this, single months with anomalous summer $P$ - $E$ events were compared with monthly means of the VRD (Fig. 3; Table 2). Generally deficient precipitation has less obvious impacts on the VRD than excessive precipitation, probably due to the existence of dams. These dams let the water pass according to the demand for electricity in the country. Normally the dams are filled in July after the snow melt and with the increase of precipitation during summer. After that, the VRD responds to the precipitation more directly. Arpe et al. (2000) therefore used annual means from July to June the following year to reduce the effect of the dam storage.

\subsection{Earlier periods with larger changes of CSL - estimate of uncertainty}

Figure 1 shows time series of different components of the water budget for the CS. This is complemented by Fig. 2. Two periods, 1993-1994 and 1995-1996 have especially strong changes in the CSL, i.e. an increase of $39 \mathrm{~cm}$ in 1993-1994 and a decrease of $21 \mathrm{~cm}$ in 1995-1996. For both periods the single components of the water budget are given in Table 3. Note that the units in Table 3 are $\mathrm{cm} \mathrm{yr}^{-1}$ to make the values of different periods comparable while the values given above are the changes for the period. The differences between anomalies of the observed VRD and $P-E$ over the VB can partly be explained by the delay between precipitation and the VRD, discussed above. So part of the excessive
Table 2. Time delays of Volga River $P-E$ extremes after $P-E$ extremes over the Volga Basin. For years earlier than 1989 data form ERA40 are used.

\begin{tabular}{lll}
\hline Date & $P-E$ event & Time delay \\
\hline Apr 1965 & maximum & 2 month \\
Apr 1974 & maximum & $\begin{array}{l}\text { 2 months, weak } \\
\text { extreme over several months }\end{array}$ \\
Jun 1979 & maximum & $\begin{array}{l}\text { 3 months, weak } \\
\text { extreme over several months }\end{array}$ \\
& & $1-2$ months \\
Jun 1996 & maximum & 1 month \\
May 1997 & maximum & 2 months, weak \\
Jul 1972 & minimum & extreme over several months \\
\hline
\end{tabular}

precipitation from 1993-1994 would only be felt in 1995 and compensate the deficit from 1995. Also the deficient precipitation for 1996 may be felt in the year to follow. For 19931994, the different components of the budget fit quite well with mismatches in the order of $5 \mathrm{~cm}$ CSL change per year, for 1995-1996 the mismatches are slightly larger.

In Table 3, the data for 2002 are given as well, a year with an increase of the CSL by $16 \mathrm{~cm}$. None of the budget components suggest such an increase. The precipitation at the Iranian coast of the CS, an area with high precipitation rates (Leroy et al., 2011), not well resolved by the analyses, was also investigated in this study as a possible source for the CSL increase. However all observations in northern Iran (IRAN, 2011) show only reduced precipitation in that year. So this strong increase of the CSL is probably an accumulation of small anomalies, smaller than the uncertainty of our calculation, of several components of the water budget. 
Table 3. Water budget component anomalies for the Caspian Sea catchment area for three periods. Units: change of the Caspian Sea level per years in $\mathrm{cm}$. For abbreviations see Table 1.

\begin{tabular}{lrrr}
\hline & $1993-1994$ & $1995-1996$ & 2002 \\
\hline CSL change & +16 & -10 & +16 \\
Observed Volga discharge & +16 & -6 & +4 \\
VB precip. ERA (GPCC) & $+7(+9)$ & $-26(-31)$ & $-13(-7)$ \\
VB evaporation & +5 & +1 & +3 \\
VB $P$ - $E$ & +12 & -25 & -10 \\
CS precipitation & +4 & -2 & +2 \\
CS evaporation & -3 & +2 & -1 \\
CS $P$ - $E$ & -1 & 0 & +1 \\
Entire CS catchment $P-E$ & +27 & -47 & -7 \\
\hline
\end{tabular}

Trenberth et al. (2011) pointed to the introduction of new observational data into the analyses schemes in late 2002: AIRS (Atmospheric Infrared Sounder) and GPS-RO (Global Positioning System - Radio Occultation). This might have affected the ERA data.

However, in 2002 a change of satellites, used for calculating the CSL, occurred from Topex-Poseidon to Jason-1. Perhaps the adjustment between the satellite data created part of this increase of CSL and therefore the CSL changes may not have been as large as shown. The gauge data of Lebedev and Kostianoy $(2005,2006)$ were used to compare their CSL anomalies (annual cycle individually removed) with those from satellite. The twelve gauges at six sites generally give very similar variabilities like the satellite data with a typical range of $10 \mathrm{~cm}$. A main exception is the second half of 2002 when all gauge observation show a decline of the CSL while the satellite data show a continuation of increase. The increase during 2002 is less than $6 \mathrm{~cm}$ in ten gauge observations, only Makhachkala has $11 \mathrm{~cm}$, while the satellite data give a $14 \mathrm{~cm}$ increase (monthly means).

From the imbalances of the budgets of the three periods an approximation of the uncertainty of the quantities can be obtained. The accuracy of the single components seems to be in the order of 5 to $10 \mathrm{~cm} \mathrm{CSL}$ change per year. As a mean precipitation of $230 \mathrm{~cm}$ CSL change per year was given in Table 1, the accuracy estimated from these episodes is 3 to $5 \%$ which is a very high demand on the accuracy of the precipitation analysis. The errors for monthly means would be $1 / 12 \cdot \sqrt{ } 12$ of the ones for annual means, if the errors are completely random, i.e. 1.4 to 2.8 , say $2 \mathrm{~cm}$ CSL change per month.

This hand-waving estimate of uncertainty can be substantiated for the error of $P-E$ over the CS itself, as the observed inflow from the Volga River and the observed CSL are available. Comparing monthly means of $P-E$ over the CS with differences of the VRD and the time derivative of the CSL after applying a 1-2-1 smoothing gives a correlation of 0.40 and a RMS error of $1.4 \mathrm{~cm}$, i.e. a slightly lower value than that obtained above. It confirms the estimates by visual inspection. Trenberth et al. (2011) give some estimates of the uncertainty of precipitation and evaporation data in reanalyses of $5-10 \mathrm{~W} \mathrm{~m}^{-2}$ which corresponds to 5$10 \mathrm{~mm}$ month $^{-1}$ or $2-4 \mathrm{~cm}$ CSL change per month from $P-E$ over the VB, which supports the values given here.

\subsection{Russian drought}

The changes of the hydrological budget for summer 2010 are highlighted in Fig. 4 and Table 4. From June 2010 onwards, one can find a steady decrease of the CSL. From the beginning of July to the end of September it is $10 \mathrm{~cm}$ (Table 4). Only $2 \mathrm{~cm}$ comes from a deficit in the VRD (observed) while the precipitation minus evaporation over the CS itself, which has an instantaneous effect on the CSL, contributes for that period a decrease of $8 \mathrm{~cm}$ of which $6 \mathrm{~cm}$ is due to the evaporation alone. The VRD together with $P-E$ over the CS explain exactly the drop of the CSL. From the $P-E$ over the VB of $-22 \mathrm{~cm}$ only $-2 \mathrm{~cm}$ impacted the CSL in this period. The remaining $20 \mathrm{~cm}$ deficit of $P-E$ will have an effect on the CSL in the following months. The CSL anomaly drops further by $7 \mathrm{~cm}$ from the beginning of October to the end of the year and further more by $5 \mathrm{~cm}$ to the end of May 2011 and the remaining $8 \mathrm{~cm}$ could still be expected if all other components of the water budget stay normal. However from October 2010 to February 2011, excessive precipitation over the Volga basin equivalent to an increase of the CSL of $7 \mathrm{~cm}$ occurred and on the other hand a deficit of $P-E$ over the VB occurred already before July 2010 equivalent to a drop of the CSL of $24 \mathrm{~cm}$ (mainly May-June) of which only $6 \mathrm{~cm}$ was observed in the VRD anomaly.

Above, the uncertainty of the budget calculations has been estimated as $2 \mathrm{~cm}$ CSL change per months and this is clearly smaller than the signal shown here.

In Fig. 5, maps of precipitation, $2 \mathrm{~m}$ temperature and evaporation over the CS catchment basin are shown for July 2010. The strongest deficit of precipitation in Fig. 5a lies over the Volga basin (heavy black line). The hottest temperatures (Fig. 5c) and the strongest decrease of evaporation (Fig. 5b) are found further south than the strongest decrease of precipitation (Fig. 5a). That is because the soil moisture, as a limiting factor for evaporation, comes into effect only where the absolute precipitation is low in relation to its anomaly. A marked southward decrease of the climatological precipitation occurs in the area, and therefore the impact of the precipitation deficit on the evaporation for 2010 lies further south. Where the soil moisture is a limiting factor for evaporation, one may expect an increase in the temperature, which is indeed seen in Fig. 5c. However, the heat wave had already a precursor in May with only slightly lower temperature anomalies than during July. At that time there was still enough water available in the soil and accordingly one finds excessive evaporation for this month over the VB (Fig. 4b). 
Table 4. Water budget component anomalies for summer 2010. Units: change of the Caspian Sea level in $\mathrm{cm}$. Differences between the sum and single month values might result from rounding. For abbreviations see Table 1 .

\begin{tabular}{lrrrr}
\hline & Jul & Aug & Sep & sum \\
\hline CSL change & -4 & -3 & -3 & -10 \\
Observed Volga discharge & -1 & -1 & -1 & -2 \\
VB precip. ERA (GPCC) & $-21(-20)$ & $-4(-2)$ & $-3(-5)$ & $-28(-27)$ \\
VB evaporation & +2 & +3 & +2 & +6 \\
VB $P-E$ (ERA) & -19 & -1 & -2 & -22 \\
CS precipitation & -1 & -0 & -1 & -2 \\
CS evaporation & -3 & -2 & -2 & -6 \\
CS $P-E$ & -4 & -2 & -3 & -8 \\
Entire CS catchment $P-E$ & -34 & -6 & -9 & -48 \\
\hline
\end{tabular}

In Fig. 5b, a strong increase of evaporation can be found over the CS itself, meaning a direct loss of water from the CS. It starts already in June and continues until September. In July 2010, the surface wind entering the CS came from the $\mathrm{E}$ to NE, while in long-term means it is from the N. So the air reaching the CS was much drier and warmer in 2010 than normal, which favours enhanced evaporation over the CS.

\subsection{ENSO impacts}

Arpe et al. (2000) and Arpe and Leroy (2007) found a connection between the CSL variability and ENSO (El Niño Southern Oscillation). It is interesting that, in Fig. 2, the time series of ONI (Oceanic Nino Index) fits well with the CSL changes for some episodes. One finds a simultaneous development of a La Niña events with a CSL drop and El Niño events with increases of the CSL, e.g. positive in 1993-1994, negative in 1995-1996, positive in 2002, negative in 2006, 2008 and in summer 2010. Only a few times this correlation fails.

The CSL changes and the VRD curves are very similar from 1993 to 2010 (Fig. 2a). In Table 5 the anomaly correlations between different parameters are given. Highest values concerning ENSO are between ONI and the CSL change and very low values between $\mathrm{ONI}$ and the VB precipitation. It has been assumed in earlier studies that ENSO affected the precipitation over the VB and by that the VRD which then had the impact on the CSL; however, the correlation coefficients just given do not support such a sequence of events.

It is planned to investigate this issue in more depth in a separate study.

\section{Discussion}

The coincidence of the CSL drop in summer 2010 with reduced precipitation over the VB and enhanced evaporation over the CS has been shown by our analysis. The drop in precipitation over the VB started in June and is strongest in July but its full effect on the CSL is not expected to be noticed

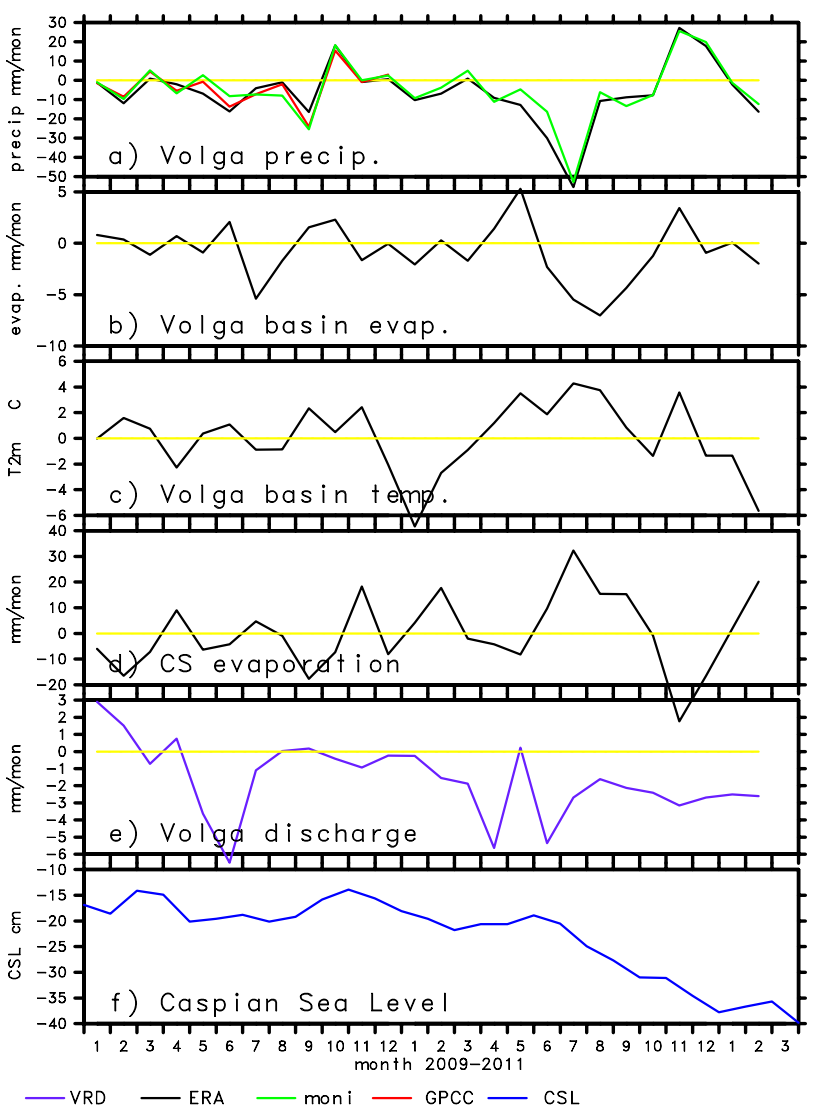

Fig. 4. Same as Fig. 1 but for 2009 to 2011 only and no smoothing.

until some months after July, as the precipitated water needs time to flow into the rivers (having previously entered the soil) and then to flow down the Volga River into the CS. It has been shown above that such a delay in the VRD for excessive precipitation is typically 2 months. However, for reduced precipitation it takes longer and is less easily seen in the data partly due to the existence of several dams which affect the water flow.

The water inflow into the major reservoirs of the VolgaKama cascade during summer 2010 was $50-70 \%$ of the normal volume. According to the Hydrometeorological Center of Russia estimates, in July 2010, the water inflow to the reservoirs of the Volga-Kama cascade was $9.9 \mathrm{~km}^{3}$ (the long-term monthly mean value is $14.2 \mathrm{~km}^{3}$ ). In August, the inflow was $6.5 \mathrm{~km}^{3}$ compared to the climatological norm of $11.5 \mathrm{~km}^{3}$. A tense hydrological situation developed in the middle and low reaches of the Volga River. In November 2010, the water level in the Kuibyshev reservoir, which is the main regulator for the runoff in the VB, was $49 \mathrm{~m}$ which is a drop of $1.05 \mathrm{~m}$ from the previous November. This means that only $37 \%$ of the usable volume of the reservoir was filled by water. The Federal Agency for Water Resources had to establish an economic regime of water discharge during the summer-autumn period of 2010. Appropriate measures to 


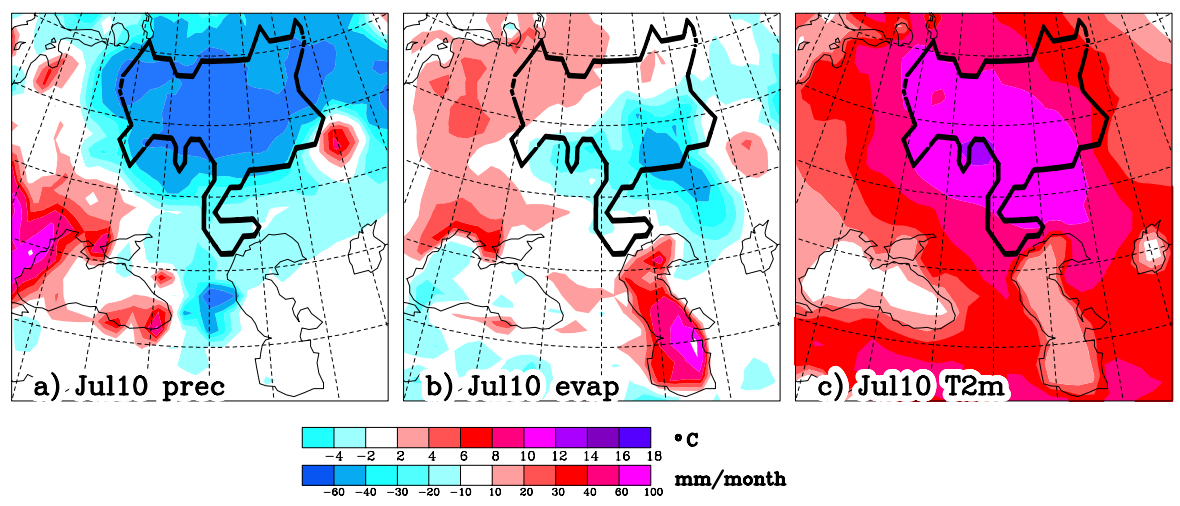

Fig. 5. Anomaly maps using ERA data. A black line indicates the Volga catchment area. (a) precipitation for July 2010; units: $\mathrm{mm}_{\mathrm{month}}{ }^{-1}$, (b) evaporation for July 2010; units: $\mathrm{mm} \mathrm{month}^{-1}$ and (c) temperature for July 2010 ; units: ${ }^{\circ} \mathrm{C}$. Red colours: increase, blue colours: decrease.

Table 5. Anomaly correlations of monthly means between Caspian Sea level (CSL) change, ENSO index (ONI), Volga River discharge (VRD) and precipitation over the Volga basin (precipVB). A 9 month running mean has been applied.

\begin{tabular}{ccccc}
\hline CSL-VRD & precipVB-VRD & CSL-ONI & VRD-ONI & precipVB-ONI \\
\hline 0.71 & 0.39 & 0.47 & 0.13 & 0.09 \\
\hline
\end{tabular}

adapt to the normal operation of the engineering infrastructure and especially municipal water supply systems to conditions of low water have been taken (FAWR, 2011). Because of the low water levels in the reservoirs, the effect of the drought on the CSL is expected to be noticed also in 2011.

Evaporation over the CS itself has however an instantaneous effect on the CSL and the additional evaporationprecipitation of $39 \mathrm{~mm} \mathrm{month}^{-1}$ in July 2010 fits very well with the observed anomalous drop of the CSL of $4 \mathrm{~cm}$ (Fig. 4; Table 4). Also for the following months the CSL drop and the evaporation over the CS itself fit very well. After that, the CSL anomaly drops further by $7 \mathrm{~cm}$ to the end of the year. This is not explained by evaporation over the CS and probably represents the delayed impact from the Russian drought.

Arpe and Leroy (2007) stated that precipitation over the VB (especially during summer) is the main driver for CSL changes. When discussing Fig. 2 and Table 5, the high anomaly correlation of 0.71 between Volga discharge and CSL change was pointed out but the connection with the precipitation was less clear. Here it is found that the evaporation variability over the CS itself has clear impacts for shorter periods, e.g. 1996, 2003 and 2010.

During a heat wave over an area one might expect enhanced evaporation. It has been shown above that this works only as long as there is enough water in the ground. If the water in the ground has been evaporated, the surface temperature increases even more.

\section{Conclusions}

Comparing the CSL variations with the impacts of the different components of the CS water budget show the impacts of the recent drought in European Russia. These new results could only be achieved due to the availability of accurate evaporation estimates provided by the ECMWF reanalysis since 1989. Meteorological, hydrological and CSL data from different sources have been used in this study and it is encouraging that they are consistent with each other. This gives confidence in their quality. In particular the ECMWF interim reanalysis data should be mentioned. These provide a wide range of data including precipitation and evaporation. The latter are created by a model because they are otherwise difficult to observe and analyze. Trenberth et al. (2011) investigated the uncertainties in reanalyses and singled out the ECMWF interim reanalysis (the one used here) as one of the best. Their warning of using such data only with extreme care does not affect this study. They are concerned about the use of such data for investigating decadal variabilities and trends because changes in the observational data entering the analysis schemes could introduce spurious changes. However their finding of a too intense water cycle over continents is supported here for the VB. Their finding of too strong evaporation over the oceans does not apply for the CS as too low evaporation is found in this study perhaps due to an underestimation of surface winds caused by the high surrounding mountains of the southern CS.

Some biases in these data still exist, but their impact in our investigation is reduced by studying anomalies which reduces the effect of systematic errors. The accuracy of the water budget data in these analyses have reached a level that an inconsistency in the satellite derived CSL data could be detected. The anomalies during and after the drought are clearly exceeding the level of uncertainty, which was estimated to be $2 \mathrm{~cm}$ CSL change per month. 
The water deficit for June to September 2010 calculated from the anomalous precipitation over the VB (Fig. 4; Table 4) would result in a decrease of the CSL by 27 to $28 \mathrm{~cm}$ (GPCC and ERA respectively). This decrease is compensated by decreased evaporation equivalent to an increase of the CSL of $6 \mathrm{~cm}$. Of the $22 \mathrm{~cm}$ water deficit, $7 \mathrm{~cm}$ had already been observed from October to the end of 2010 and a further $5 \mathrm{~cm}$ to the end of May 2011. A further drop, with impacts on human activities on and around the CS (e.g. harbour accessibility, petroleum and caviar industries), is therefore to be expected. Some scope for making forecasts of the CSL a few months ahead seems feasible. This may turn out to be an essential contribution to the mitigation of societal impacts of CSL changes.

Acknowledgements. This article is a contribution to the European project Marie Curie, CLIMSEAS-PIRSES-GA-2009-247512: "Climate Change and Inland Seas: Phenomena, Feedback and Uncertainties. The Physical Science Basis". We thank Andrew Russell from Brunel University to comment on an earlier version of this paper. M. Turner (Brunel University) has kindly revised the English of the manuscript. We thank the anonymous reviewers and Stephen Kershaw from Brunel University for their constructive comments.

We thank Andrey Kostianoy and Sergey_Lebedev for providing the CSL gauge data.

The service charges for this open access publication have been covered by the Max Planck Society.

Edited by: B. van den Hurk

\section{References}

Arpe, K. and Leroy, S. A. G.: The Caspian Sea Level forced by the atmospheric circulation as observed and modelled, Quatern. Int., 173-174, 144-152, 2007.

Arpe, K., Bengtsson, L., Golitsyn, G. S., Mokhov, I. I., Semenov, V. A., and Sporyshev, P. V.: Connection between Caspian Sea level variability and ENSO, Geophys. Res. Lett., 27, 2693-2696, 2000.

Barriopedro, D., Fischer, E. M., Luterbacher, J., Trigo, R. M., and García-Herrera, R.: The Hot Summer of 2010: Redrawing the Temperature Record Map of Europe, Science, 332, 220-224, 2011.

Cazenave, A., Bonnefond, K., Dominh, K., and Schaeffer, P.: Caspian Sea Level from Topex-Poseidon altimetry: Level now falling, Geophys. Res. Lett., 24, 881-884, 1997.

CPC: available at: http://www.cpc.ncep.noaa.gov/products/ analysis_monitoring/ensostuff/ensoyears.shtml, last access: 20 May 2011.

Dee, D. P., Uppala, S. M., Simmons, A. J., Berrisford, P., Poli, P., Kobayashi, S., Andrae, U., Balmaseda, M. A., Balsamo, G., Bauer, P., Bechtold, P., Beljaars, A. C. M., van de Berg, L., Bidlot, J., Bormann, N., Delsol, C., Dragani, R., Fuentes, M., Geer, A. J., Haimberger, L., Healy, S. B., Hersbach, H., Hólm, E. V., Isaksen, L., Kållberg, P., Köhler, M., Matricardi, M., McNally,
A. P., Monge-Sanz, B. M., Morcrette, J.-J., Park, B.-K., Peubey, C., de Rosnay, P., Tavolato, C., Thépaut, J.-N., and Vitart, F.: The ERA-Interim reanalysis: configuration and performance of the data assimilation system, Q. J. Roy. Meteor. Soc., 137, 553597, doi:10.1002/qj.828, 2011.

Dümenil Gates, L., Hagemann, S., and Golz, C.: Observed historical discharge data from major rivers for climate model validation, Max-Planck Institute for Meteorology, Hamburg, Report no. 307, 93 pp., 2000.

ECMWF: available at: http://data-portal.ecmwf.int/data/d/interim_ daily/, last access: 20 May 2011.

FAWR: Press release of the federal agency of water resources of the Russian Federation, available at: http://gfu-volga.ru, issued 15 November 2010, last access: 27 January 2011 (in Russian).

Golitsyn, G. S.: The Caspian Sea level as a problem of diagnosis and prognosis of the regional climate change, Izv. Russ. Acad. Sci. Atmos. Oceanic Phys., Engl. Trans., 31, 366-372, 1995.

GPCC: available at: ftp://ftp-anon.dwd.de/pub/data/gpcc/html/ fulldata_download.html and ftp://ftp-anon.dwd.de/pub/data/ gpcc/html/gpcc_monitoring_v3_download.html, last access: 20 May 2011.

IRAN: http://www.irimo.ir/english/, last access: 22 May 2011.

Kislov, A. and Toropov, P.: East European river runoff and Black Sea and Caspian Sea level changes as simulated within the Paleoclimate modeling intercomparison project, Quatern. Int., 167168, 40-48, 2007.

Lahijani, H., Leroy, S., Beni, M. N., and Arpe, K.: Blaze in Volga: Is it a critical point for the fall in Caspian Sea level?, News Report Episodes, 33, 208-208, 2010.

Lebedev, S. A. and Kostianoy, A. G.: Satellite Altimetry of the Caspian Sea, Moscow, Sea, 366 pp., 2005 (in Russian).

Lebedev, S. A. and Kostianoy, A. G.: Integrated Use of Satellite Altimetry in the Investigation of the Meteorological, Hydrological, and Hydrodynamic Regime of the Caspian Sea, Terr. Atmos. Ocean. Sci., 19, 1-2, 71-82, 2008.

Leroy, S. A. G., Lahijani, H. A. K., Djamali, M., Naqinezhad, A., Moghadam, M. V., Arpe, K., Shah-Hosseini, M., Hosseindoust, M., Miller, Ch. S., Tavakoli, V., Habibi, P., and Naderi, M.: Late Little Ice Age palaeoenvironmental records from the Anzali and Amirkola Lagoons (south Caspian Sea): Vegetation and sea level changes, Palaeogeogr. Palaeocl., 302, 415-434, 2011

Meleshko, V. P., Kattsov, V. M., Govorkova, V. A., Sporyshev, P. V., Shkol'nik, I. M., and Shneerov, B. E.:Climate of Russia in the 21st Century. Part 3. Future Climate Changes Calculated with an Ensemble of Coupled Atmosphere-Ocean General Circulation CMIP3 Models, Meteorologiya i Gidrologiya, 9, 5-21, 2008.

Ozyavas, A., Khan, S. D., and Casey, J. F.: A possible connection of Caspian Sea level fluctuations with meteorological factors and seismicity, Earth Planet. Sc. Lett., 299, 150-158, 2010.

Parshina, L.: Weather outlook over Russia in August 2010, Meteorology and Hydrology, 11, 100-104, 2010 (in Russian).

Rodionov, S. N.: Global and Regional Climate Interaction: The Caspian Sea Experience, Kluwer Academic Publications, Dordrecht, The Netherlands, 241 pp., 1994.

Rudolf, B., Fuchs, T., Schneider, U., and Meyer-Christoffer, A.: Introduction of the Global Precipitation Climatology Centre (GPCC), Deutscher Wetterdienst, Offenbach a.M.; 16 pp., available on request per email gpcc@dwd.de or by download from GPCC's Website, 2003. 
Sevruk, B.: Methods of correction for systematic error in point precipitation measurement for operational use, Operational Hydrology Rep., 21, World Meteorological Organization, Geneva, 91 pp., 1982.

Trenberth, K. E., Fasullo J. T., and Mackaro, J.: Atmospheric moisture transports from ocean to land and global energy flows in reanalyses, J. Climate, 24, 4907-4924, doi:10.1175/2011JCLI4171.1, 2011.

Uppala, S. M., Kållberg, P. W., Simmons, A. J., Andrae, U., da Costa Bechtold, V., Fiorino, M., Gibson, J. K., Haseler, J., Hernandez, A., Kelly, G. A., Li, X., Onogi, K., Saarinen, S., Sokka, N., Allan, R. P., Andersson, E., Arpe, K., Balmaseda, M. A., Beljaars, A. C. M., van de Berg, L., Bidlot, J., Bormann, N., Caires, S., Chevallier, F., Dethof, A., Dragosavac, M., Fisher, M., Fuentes, M., Hagemann, S., Hólm, E., Hoskins, B. J., Isaksen, L., Janssen, P. A. E. M., Jenne, R., McNally, A. P., Mahfouf, J.-F., Morcrette, J.-J., Rayner, N. A., Saunders, R. W., Simon, P., Sterl, A., Trenberth, K. E., Untch, A., Vasiljevic, D., Viterbo, P., and Woollen, J.: The ERA-40 re-analysis, Q. J. Roy. Meteor. Soc., 131, 2961-3012, 2005.
USDA: available at: http://www.pecad.fas.usda.gov/cropexplorer/ global_reservoir/gr_regional_chart.cfm?regionid=metu\&region $=\&$ reservoir_name $=$ Caspian, last access: 20 May 2011. 